\title{
O RETRATO DE PROFESSORAS DE LÍNGUA INGLESA: POR UMA LEITURA DECOLONIAL DO CINEMA
}

\author{
THE PORTRAIT OF WOMEN ENGLISH LANGUAGE TEACHER: \\ FOR A DECOLONIAL READING OF MOTION PICTURE
}

Recebido: 15/10/2021

Aprovado: $24 / 11 / 2021$

Publicado: 22/12/2021

DOI: $10.18817 /$ rlj.v5i2.2680

\author{
Ana Paula Domingos Baladeli ${ }^{1}$ \\ Orcid ID: https://orcid.org/0000-0001-8508-0350 \\ Rinaldo Vitor da Costa ${ }^{2}$ \\ Orcid ID: https://orcid.org/0000-0003-4289-8739
}

\begin{abstract}
Resumo: O cinema representa uma técnica, indústria, arte, mas também um discurso, e como tal, dissemina valores culturais e ideológicos daqueles que o produzem (DALTON, 2010; CANN, 2015). O discurso como prática social (FAIRCLOUGH, 2001), e a Pedagogia Crítica são o pano de fundo para a discussão sobre a docência do professor branco em escolas periféricas nos filmes Dangerous Mind (1995) e Freedom Writers (2007). O objetivo deste estudo é discutir, a partir do retrato de professoras protagonistas de Língua Inglesa no cinema, o ideário colonialista de educação. Os resultados evidenciam a não neutralidade do discurso cinematográfico no sentido de perpetuar estereótipos de professores brancos salvadores, que no auge de sua compaixão conduzem os estudantes negros e latinos da periferia no caminho do conhecimento e da redenção.
\end{abstract}

Palavras-chave: Professor. Discurso cinematográfico. Língua Inglesa. Decolonialidade.

Abstract: The motion picture represents a technique, industry, art, but also is a discourse, and as such, disseminate cultural and ideological values those sho produce it (DALTON, 2010; CANN, 2015). Discourse as social practice (FAIRCLOUGH, 2001) and Critical Pedagogy are the background to discussion about white teacher teaching in peripheral schools in motion pictures, Dangerous Mind (1995) and Freedom Writers (2007). The aim of this study is to discuss based on the portrait of women English language tearcher in motion picture the ideals colonialist education. The outcomes indicate the non-neutrality of cinematic discourse in sense of perpetuating stereotypes of white savior teachers, who act at the height of compassion, they lead black and latin students from periphery on the path of knowledge and redemption.

Keywords: Teacher. Cinematic discourse. English language. Decoloniality.

\section{Introdução}

No escopo da Linguística Aplicada, doravante LA, importa à educação como processo de humanização, a formação crítica a partir de uma concepção de língua

\footnotetext{
1 Licenciada em Letras Português e Inglês (2004), Mestre em Educação (2009), Mestre em Letras (2012), Doutora em Letras (2015). Tem desenvolvido pesquisas básicas e empíricas na área de Educação e Linguística Aplicada com foco na formação de professores. O principal tema das pesquisas e projetos é a formação do professor a partir das contribuições da Teoria dos Multiletramentos. Líder do Grupo de Estudos Laboratório dos Multiletramentos, Cibercultura e Educação - LAMCE. E-mail: apdbaladeli@gmail.com

2 Doutor em Linguística Aplicada. Professor de línguas adicionais na Universidade Federal da Integração LatinoAmericana - UNILA, PR. E-mail: rinaldo67@hotmail.com
} 
como prática social situada, que considere os efeitos dos fenômenos socioculturais nos processos de ensino e aprendizagem de línguas (MOITA LOPES, 2006; PEREIRA, 2015). O discurso sobre os aspectos positivos da educação formal como fenômeno per se responsável pela transformação social, ratifica a escola como espaço sui generis pela correção de mazelas e desigualdades sociais. A depender da concepção de educação e dos propósitos a que servem, a escola pode legitimarse como agência propagadora da cultura letrada, escamoteando a diversidade cultural, sexual e racial (hooks, 1994).

No bojo de uma sociedade capitalista, portanto, excludente, reposiciona-se a figura do professor como agente direto entre a educação e o estudante, capaz de consolidar a mudança de atitudes e a aceitação de verdades representativas de valores hegemônicos (MOITA LOPES, 2006). Deste modo, alinha-se aos propósitos da LA a Pedagogia Crítica Decolonial (ZABALA, 2016; TAKAKI, 2020), epistemologia que questiona os currículos como instrumentos ideológicos, estes que operam normatizando valores hegemônicos e naturalizando desigualdades sociais.

Importa ao ensino de línguas estrangeiras na perspectiva crítica, o desvelamento de valores hegemônicos presentes no currículo, na didática, no exclusivismo linguístico, resultado do imperialismo disseminado pela Língua Inglesa (PHILLIPSON, 1992) e, sobretudo nos discursos que consolidam relações de poder (hooks, 1994; FAIRCLOUGH, 1995, 2001).

Para hooks (1994), promover a Pedagogia Crítica exige o engajamento e a conscientização dos estudantes, com vistas a questionar quais vozes ecoam na sala de aula, e quais significados, valores e visões de mundo são propagados. A pesquisadora reflete sobre os padrões hegemônicos que balizam e legimitam os conhecimentos valorizados na escola. hooks ainda assevera que a sala de aula é um espaço plural e de embate, portanto, a Pedagogia Crítica como epistemologia opera como movimento de contestação e resistência na desconstrução do mito da homogeneidade cultural, sexual e racial.

A LA como área transdisciplinar favorece o questionamento de fenômenos socioculturais que atravessam os processos de ensino e aprendizagem de línguas, bem como problematiza os efeitos de seus desdobramentos na prática pedagógica (MOITA LOPES, 2006). Isto posto, nos interessa relacionar os significados construídos sobre a profissão professor, no discurso cinematográfico hollywoodiano, 
a partir da caracterização de duas professoras de Língua Inglesa. O referido objeto de análise nos possibilita discutir a influência de referências culturais na caracterização da docência, além de possibilitar a discussão sobre os significados de ensinar e aprender Língua Inglesa.

Tomando o cinema como discurso, uma análise de filmes sobre escola, ou seja, aqueles em que o (a) protagonista é um(a) professor(a), favorece a ampliação de análises críticas sobre os significados naturalizados de docência e o papel da Língua Inglesa na condução do ajustamento ao sistema.

Em análise de narrativas fílmicas sobre a profissão professor, Bulman (2002), Dalton, (2010), Fabris (2010), Cann (2015), constataram semelhanças nos enredos que apresentam o professor protagonista. Não é exagero afirmar que consertar ou transformar os estudantes latinos, negros e da periferia, se torna o projeto pessoal das professoras outsiders do cinema. O retrato do professor missionário, benevolente, caridoso e bem intencionado, que faz de seu trabalho uma missão de vida, expressa um projeto de educação colonialista, explorando para isso a relação dominante $\mathrm{x}$ dominado, civilizado $\mathrm{x}$ não civilizado como elementos do enredo.

Diante isso, considerando a abrangência do cinema como discurso, não raro identificamos a caracterização do professor como sinônimo de sacrifício, dado que propaga sentidos sobre o bom professor ou professor herói. No caso da abrangência das produções hollywoodianas, pesquisas de Dalton (2010); Cann (2015); Aronson (2017); Baladeli (2019) discutem a dimensão cultural de tais produções, as formas particulares com que a indústria cinemagráfica padroniza as característas da personagem professor, sobretudo, professoras de Língua Inglesa que atuam em escolas periféricas.

Considerando o discurso como prática social, que congrega relações de poder e ideologias em sua composição, conforme discute Fairclough (2001), os textos não são neutros, visto que congregam indicíos de ideologias e valores. Com isso, o objetivo deste estudo é discutir, a partir do retrato de professoras protagonistas de Língua Inglesa, nos filmes Mentes Perigosas - Dangerous Mind (1995) e Escritores da Liberdade - Freedom Writers (2007), a proposta da educação colonialista.

\section{As contribuições da Teoria Decolonial}


Segundo Phillipson (1992), a língua funciona como um artefato que propaga repertórios culturais valorizados, hegemônicos, representativos da lógica dominante. A língua em si não se caracterizaria como instrumento opressor, mas a interface desta com aspectos históricos e geopolíticos, dão o contorno à Língua Inglesa, como língua associada ao poder. Não seria exagero afirmar, que o imperialismo linguístico e seus efeitos, conforme debatido por Phillipson (1992), corrobaram na manutenção de outras formas de controle, como social, cultural, racial e sexual. Em última análise, o desejo de aprender a Língua Inglesa e as benesses naturalmente associadas à sua aquisição, consolidaria o status da língua no cenário global, despertendo o sentido de pertencimento e poder.

Com isso, o pensamento decolonial e sua influência no ensino de línguas, promoveria a lógica da colonialidade do poder, ou seja, a propagação de formas de significação, valores e crenças de determinada matriz cultural. O rompimento desta cadeia ideológica de significação exige $\circ$ rompimento de referenciais epistemológicos dominantes, por vezes eurocêntricos (DULCl e MALHEIROS, 2021).

Pensar metodologias decoloniais é pensar outras ferramentas além das que hierarquizam e objetivam povos e vozes subalternizados e silenciados. Não por acaso, por todo o tempo, reafirmamos que as pesquisas não são neutras e que o conhecimento está hierarquizado a partir da 'colonialidade do poder' (p.191).

Transpondo a educação crítica na Perspectiva Decolonial para o debate sobre os enredos com professoras de Língua Inglesa protagonistas, podemos confrontar o discurso hegemônico de educação, língua e cultura propagados por Hollywood. Com base nas contribuições da Pedagogia Decolonial (MIGNOLO e VÁZQUEZ, 2017), abordamos o tema da profissão professor, em específico de professoras de Língua Inglesa a partir do discurso cinematográfico.

Nosso ponto de partida é a concepção de língua como sistema neutro, a qual refutamos com base em Pereira (2015), que discute os aspectos ideológicos e seus reflexos na naturalização associada à aprendizagem de Língua Inglesa como uma benesse sociocultural. Historicamente, a Língua Inglesa assumiu a posição de destaque no cenário geopolítico global não por mera casualidade, mas devido a questões socioeconômicas, exploração, relações de poder e interesses comerciais. 
Para a pesquisadora, naturalizar a Língua Inglesa como língua internacional traz à reboque, a aceitação do imperalismo linguístico e todos os impactos a ele inerentes.

O discurso socialmente propagado e/ou naturalizado é o de que o domínio da Língua Inglesa garantiria melhores oportunidades de participação na sociedade globalizada. O imperialismo cultural e linguístico conforme discute Phillipson (1992) opera não só na reprodução das condições materiais de exploração do Centro para a Periferia, como também na internalização de seus modos de significação.

O discurso contribui para a constituição de todas as dimensões da estrutura social que, direta ou indiretamente, o moldam e o restringem:

suas próprias normas e convenções, como também relações, identidades e instituições que lhe são subjacentes. O discurso é uma prática, não apenas de representação do mundo, mas de significação do mundo, constituindo e construindo o mundo em significado (FAIRCLOUGH, 2001, p. 91).

Sendo assim, o discurso como ação intencional e concreta nas práticas sociais, os textos viabilizam eventos sociais que se relacionam dialeticamente aos elementos não discursivos, logo, no contexto das transformações sociais, os textos oferecem indícios das práticas sociais de onde circulam (FAIRCLOUGH, 2001).

As ideologias surgem nas sociedades caracterizadas por relações de dominação com base na classe, no gênero social, no grupo cultural, e assim por diante, e à medida que os seres humanos são capazes de transcender tais sociedades, são capazes de transcender a ideologia (FAIRCLOUGH, 2001, p. 121).

Nesses termos, seja como Língua Internacional ou Língua Franca, a Língua Inglesa propaga-se como commodity valorizado e objeto do desejo de países periféricos, pois através dela se acessa um repertório cultural valorizado (PEREIRA, 2015). O cenário perpetua a dimensão ideológica e a falácia da neutralidade do conhecimento, em outras palavras, globalmente, as identidades e os valores locais não saem incólumes dos impactos do imperialismo cultural e linguístico da Língua Inglesa e seus modelos de cultura dominante. Fato inconteste, o imperialismo linguístico, conforme abordado por Phillipson (1992), se expande para outras formas de dominação, tornando estrutural a submissão de padrões de comportamento e valores locais pela língua e cultura dominantes considerados melhores, civilizados e representativos de progresso. 
A questão central que serve de pano de fundo é que a escola agencia a propagação de valores culturais, por meio do currículo, este que consolida a homogeneização dos conhecimentos. Na obra Escritos de Educação organizada por Nogueira e Catani (2007), Bourdieu discute e problematiza, a partir do conceito de violência simbólica, o lugar da cultura valorizada e seu papel como repertório de referência na escola.

São as funções latentes que essas classes atribuem a instituição escolar, a saber, organizar o culto de uma cultura que pode ser proposta a todos, porque está reservada de fato aos membros das classes às quais ela pertence. É a hierarquia dos valores intelectuais que dá aos manipuladores prestigiosos de palavras e ideias superioridade sobre os humildes servidores de técnicas (NOGUEIRA e CATANI, 2007, p. 56).

Desnecessário dizer, que na escola como instituição guardiã do saber científico há conhecimentos em disputa, ou seja, confrontos e incompatibilidades entre os conhecimentos e valores locais com os conhecimentos valorizados, chancelados pelo currículo e pelos discursos.

Nos propósitos deste estudo, o cinema como técnica, arte ou discurso mobiliza um conjunto de significados e repertórios culturais que impactam a forma como, no caso de filmes sobre professores, se sentem ou não representados nos enredos.

\section{A docência no discurso cinematográfico}

O cinema como arte, extravasa o lirismo narrativo por meio de recursos de edição e produção com foco na experiência estética do espectador com o enredo. Mesmo nessa circunstância, não podemos desconsiderar a função estética do cinema, ao selecionar, interpretar e narrar sob diferentes gêneros de filme a profissão docente.

O discurso propagado pela indústria cinematográfica pode, segundo Teixeira, Grammont e Azevedo (2014), tanto justificar as representações de mundo construídas pelos espectadores, quanto fornecer novos significados sobre a profissão para professores (TEIXEIRA, GRAMMONT, AZEVEDO, 2014). 
Esse outro inunda as telas de cinema, em películas que contribuem na reflexão sobre os professores, seus atributos e condições sociais e focalizam diferentes experiências dos rituais da docência em diferentes planos e variadas perspectivas, articulando arte e vida, escola e vida social, iluminando os vínculos entre educação, cultura e sociedade, em suas temporalidades históricas (TEIXEIRA, GRAMMONT e AZEVEDO, 2014, p. 128).

Por óbvio, protagonistas professores que assumem a sala de aula de escolas periféricas e enfrentam toda sorte de obstáculo, incorporam para si a solução de questões sociais, culturais e históricas que acometem as turmas problemáticas nas quais lecionam.

Segundo Cann (2015), a agenda hollywoodiana de narrativas sobre professores protagonistas novatos ou outsider, que atuam como salvadores em escolas periféricas, está diretamente relacionada ao programa Teach for America TFA. O referido programa concede certificado de docência aos participantes, universitários novatos, que iniciam na docência em escolas públicas estadunidenses de baixa renda e com baixo rendimento nas avaliações oficiais. Ao receberem capacitação no programa, os estudantes assumem a sala de aula em escolas rurais, periféricas com baixa performance nas avaliações e alto índice de evasão. Para Cann (2015), a ideologia do TFA coadunou-se às produções culturais como o cinema, dando forma e conteúdo ao discurso do sacrífício individual, ou seja, do personalismo, propagando naquele contexto representações de docência alinhadas à lógica do herói cinematográfico.

Assim, a ficção imita a realidade, ao retratar no cinema a jornada de um outsider (DALTON, 2010), que sem experiência prévia na docência assume a sala de aula sem didática ou epistemologias definidos. O alcance global da indústria cultural hollywoodiana progaga concepções de mundo, valores e significados próprios de seu país de origem, impactando, contrastando e por vezes, subjulgando significados locais dos países receptores das produções culturais estadunidenses. Isso ocorre, segundo Fabris (2010), porque os filmes como produtos da cultura do entretenimento operam como referências, sobretudo para jovens, que na lógica do espelho se projetam nos enredos incorporando as personagem como representações de si. "Quando essa pedagogia vem marcada pelos valores tradicionais de uma cultura, temos um campo propício para a colonização cultural" (FABRIS, 2010, p. 234). 
Dito de outro modo, os enredos e o audiovisual de modo geral, tornam-se instrumento de uma dada cultura replicada globalmente, afetando as concepções assumidas por jovens ao redor do globo, que se projetam nas personagem romantizadas ou caricatas do cinema. Considerando as contribuições das análises sobre as representações da docência no cinema de Bulman (2002), Dalton (2010), Fabris (2010), Aronson (2017), Baladeli (2019), a naturalização da escola como espaço sine qua non de civilização de grupos problemáticos, sugere a perpetuação de visões dominantes de valores culturais, atribuindo ao professor, o papel de consertar, encaixar e sobretudo, salvar os estudantes oriundos de grupos minoritários.

\section{A professora no cinema ou sobre a agenda colonialista}

As contribuições das análises críticas do discurso da mídia com base em Fairclough (1995), destacam a atividade de interpretação sobre que tipos de identidades sociais, representações de si e de modelos culturais são propagados em textos de diferentes gêneros, no caso deste estudo, o discurso do cinema. O corpus deste estudo é composto por duas narrativas fílmicas, quais sejam; Dangerous Mind - Mentes Perigosas (1995) e Freedom writers - Escritores da Liberdade (2007). As narrativas foram selecionadas por apresentarem professoras brancas de Língua Inglesa que atuam em escolas multiculturais da periferia estadunidense.

As professoras Louanne Johnson (Michelle Pfeiffer) e Erin Gruwell (Hillary Swank, começam suas jornadas na docência em escolas multiculturais, em turmas com problemas de indisciplina e déficit de aprendizagem. De início, reconhecem as limitações do próprio sistema educacional, este que inibe a criatividade docente e oprime o desenvolvimento do pensamento crítico por meio da impósição de um currículo descontextualizado.

Nossas reflexões se valem das contribuições da Pedagogia Decolonial (MIGNOLO e VÁZQUEZ, 2017), que problematiza o caráter opressor que as instituições de ensino e as concepções de educação podem imprimir a estudantes e professores. Para Mignolo e Vázquez (2017), a concepção de educação assume função precípua na Universidade, espaço que contribui para efetivar a dominação na medida em que perpetua a exclusividade da educação via conjunto de 
conhecimentos e valores hegemônicos. Reproduzindo assim, ainda que de forma subjacente, a visão assimétrica entre o conhecimento considerado válido socialmente e os valores e conhecimentos populares.

$\mathrm{Na}$ lógica dos opostos centro $\mathrm{x}$ periferia, civilizado $\mathrm{x}$ não civilizado, superior $\mathrm{x}$ inferior, temos nas personagens de Johnson e Gruwell, a personificação do ideário hegemônio de cultura e valores civilizados. Ao assumir a docência de Língua Inglesa em escolas de periferia, as professoras representam a solução para problemas de aprendizagem e disciplinares dos estudantes daquelas turmas. O perfil dos estudantes de ambas as escolas é similar. São jovens negros e latinos, oriundos da periferia, são retratados como indisciplinados, rebeldes, descompromissados com os estudos, sem expectativas educacionais, apresentam dificuldades de aprendizagem de Língua Inglesa. Seus familiares não esboçam compromisso com a educação dos filhos, parte porque também não acreditam que o sistema educacional contemple as demandas e especificidades de seu grupo social.

As narrativas nos apresentam as escolas de periferia como espaço de conflito racial, social e de gênero. Estudantes e professores vivenciam embates de várias ordens, numa atmosfera de animosidade e tensão constantes, o que desencadeia na gestão a anomia e nos estudantes a rebeldia. Todavia, conforme preconiza a perspectiva colonializadora de educação, o cenário é alterado com a chegada das professoras brancas, educadas, baluarte da intelectualidade e da civilidade, nos respectivos filmes Mentes Perigosas, Louanne Johnson (Figura 01), e Escritores da Liberdade, Erin Gruwell (Figura 02).

Figura 1

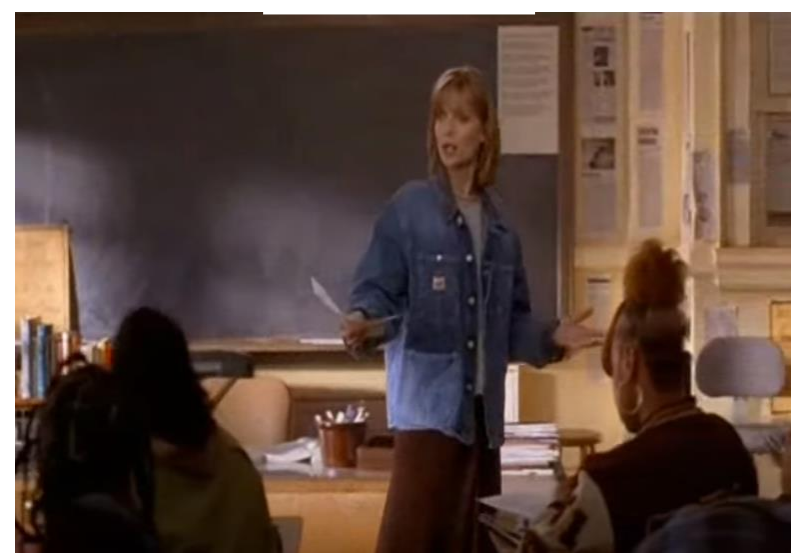

Fonte: Dangerous Mind (1995)
Figura 2

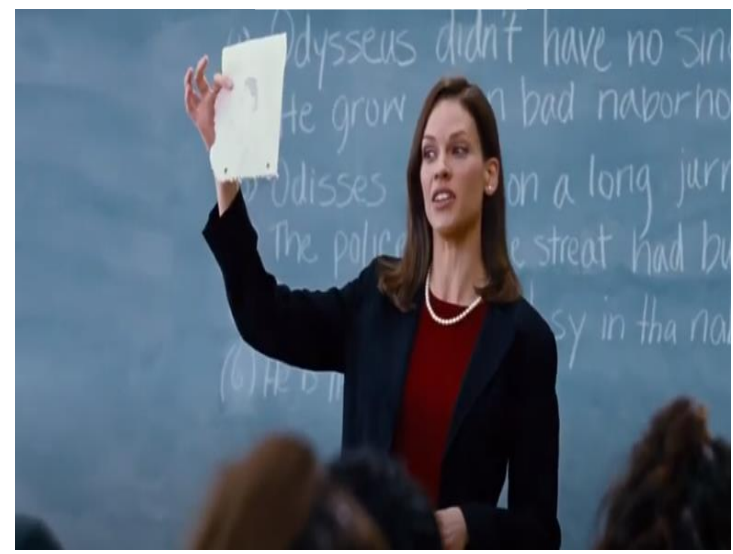

Fonte: Freedom Writers (2007) 
As relações de poder estão explicitamente presentes nos enredos. Assim, mesmo que imbuidas de boas intenções, as professoras que chegam para fazer a transformação do que precisa ser transformado, nos remete ầ lógica do colonizador. Logo, a disciplina de Língua Inglesa cumpre a função de perpetuar a relação assimétrica entre a língua representada nos livros e a tradição cultural dominante. Para Fabris (2010), a professora outsider Louanne Johnson é uma professora extraordinária, bela e elegante, expontânea, ex-oficial da Marinha que assume a docência como mais um trabalho.

Os estudantes não civilizados, carentes de valores e repertório da cultura erudita, são transformados pela didática, ou nas palavras de Fabris (2010) pela Pedagogia do Herói, que via personalismo, garante o happy end hollywoodiano. Nos estudos de Dalton (2010), o cinema reproduz o retrato do professor outsider, como aquele novato bem intencionado, que a princípio é mal recebido pela comunidade escolar, é desacreditado pela própria gestão da escola que aposta na sua inaptidão para aquele contexto escolar. Entretanto, ao longo das narrativas, as professoras outsider subvertem as previsões da gestão, desafiam os familiares e conquistam o respeito dos estudantes, superando os obstáculos e cumprindo sua jornada do herói.

As narrativas ilustram o desvio como o ponto fulcral para atuação de uma professora extraordinária, que dotada de compaixão, impõe sua pedagogia embebida na lógica colonial, na didática como instrumento de uma nova proposta de educação. Não por acaso, endireitar ou consertar a turma, considerada problemática e rebelde, é o elemento-chave dos enredos hollywoodianos que exploram protagonistas brancos como guardiões da sabedoria e dos conhecimentos hegemônicos que faltam aos estudantes. O descaso da gestão também se faz presente nos encaminhamentos dados às professoras novatas, indiciando o modus operandi da assimetria entre a escola e a comunidade.

Nos serve aos propósitos da discussão ensejada, as contribuições sobre a lógica do branco privilegiado, presente nos estudos de Aronson (2017). Em outros termos, há um discurso incorporado e naturalizado no imaginário social e propagado pelo cinema, que diz respeito aos brancos abastados da América do Norte e suas ações benevolentes em países e/ou continentes menos favorecidos. Com isso, apregoa-se que o branco salvador, bem intencionado, abidica de seu tempo e 
energia na solução de problemas dos menos afortunados, a que Aronson (2017) caracteriza como projetos hegemônicos de branquitude.

Nessa perspectiva, o discurso cinematográfico corrobora na propagação do ideário do salvacionismo do professor branco, que em sendo privilegiado, dedica-se a salvar seus alunos problemáticos de sua condição na sociedade, buscando ainda recompensá-los pela falta de acesso aos benefícios a que demais classes sociais desfrutam. Com a atuação da professora Johnson de Mentes Perigosas, há a ressignificação da aula de Língua Inglesa com textos literários, que passa a contar com a leitura de letras de música. A professora propõe o desafio Dylan Dylan, que consistiu na pesquisa de um poema de Dylan Thomas e uma letra de música com tema correspondente de autoria do compositor Bob Dylan. À princípio, a iniciativa é questionada pelos estudantes que não veem sentido na tarefa, mas a professora consegue convencê-los sobre a relevância da atividade.

Fabris (2010), Cann (2015) e Aronson (2017) discutem a naturalização da do professor herói no discurso cinematográfico, que retrata o professor branco como determinado a construir um laço afetivo com a turma. Os professores outsider são caracterizados como carismáticos, resilientes e obstinados, desafiando a gestão escolar e até os familiares dos estudantes. A romantização da figura do professor salvador, encapsula e romantiza a profissão, escamoteando as idiossincrasias inerente à educação. Além disso, atribui e personifica no professor a capacidade de solucionar todo e qualquer problema vivenciado pelos estudantes oriundos das classes populares, por meio de estratégias questionáveis de ensino, que visam a instituição de novos comportamentos. Ou seja, ao torná-los dóceis, menos revoltados e cooperativos, a aprendizagem aconteceria como consequência, e todas as mazelas sociais, diferenças de cultura, conflitos raciais, sexuais e sociais, até então patentes, seriam minimizados se a sala de aula de Língua Inglesa se tornar um espaço amistoso e homogêneo.

As professoras de Mentes Perigosas e Escritores da Liberdade, lecionam Língua Inglesa, lançam mão de estratégias didáticas pouco usuais, como a premiação pela realização de tarefas, custeio de passeios com os estudantes, subversão da relação profissional professor-aluno, visitas às casas dos estudantes, estabelecimento de um laço mais estreito com estudantes, e estabelecem confronto direto com a direção escolar. Os enredos se repetem, sob a lógica de que os 
professores extraordinários "[...] precisam enfrentar o sistema, Hollywood indica pontos de deslocamentos do poder, embora em suas histórias geralmente o poder esteja posicionado no sistema e permaneça com ele no final" (FABRIS, 2010, p. 237).

Gruwell por sua vez, contextualiza o ensino de Língua Inglesa por meio de narrativas autobiográficas, fazendo um contrapondo com os estudos sobre a temática do Holocausto e a leitura da obra Diário de Anne Frank. Ao descobrir que o currículo previa a leitura de obras adaptadas e não clássicas, a professora busca apoio do conselho escolar para inserir novas obras no currículo, ao que recebe a negativa da gestão. Obstinada, custeia a aquisição da obra e distribui aos estudantes, a partir da qual iniciam a prática de escrita autobiográfica dos estudantes, subvertendo as obras listadas no currículo consideradas com pobreza de linguagem.

No excerto (Figura 03), observamos o embate entre a professora Gruwell e a estudante Eva, que discutem sobre o lugar de fala de brancos e negros na sociedade. A professora se mostra ofendida pelo fato de os estudantes não demonstrarem confiança em sua atuação, discurso que é atravessado pela condição dos estudantes negros, latinos e de periferia que vivenciaram o descaso, 0 preconceito e a violência social.

Figura 03

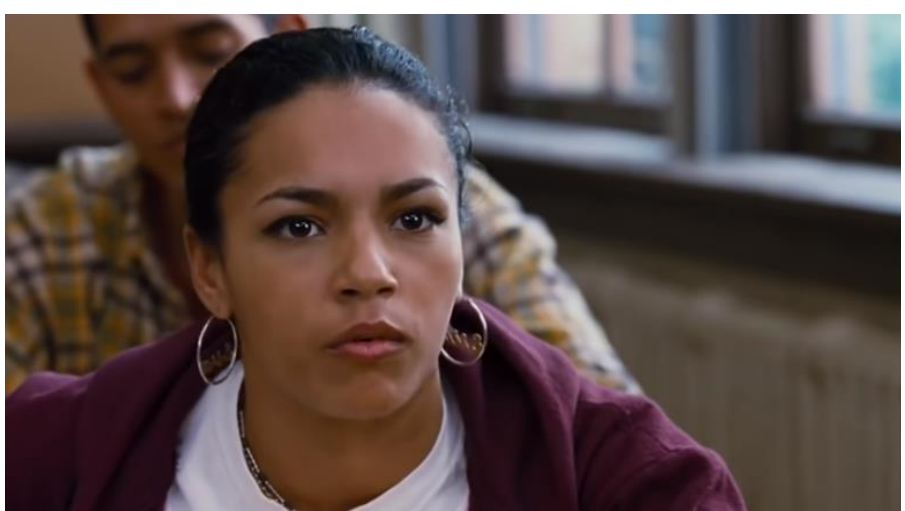

Fonte: Freedom Writers (2007).

Ms. Gruwell: I'm a teacher, it doesn't matter what color I am.

Eva: It's all about color. It's about people deciding what you deserve, about people wanting what they don't deserve. About whites thinking they run this world no matter what, you see, I hate white people.

Ms. Gruwell: You hate me? You don't even know me.

Eva: I know what you can do. I saw white cops shoot my friend in the back for reaching into his pocket, hist pocket! I saw white cops come into my 
house and take my father away for no REASON except they feel like it! Except because they can! And they can, because they're white. So I HATE white people on sight! (FREEDOM WRITERS, 2007).

O enredo retrata pais resistentes e ignorantes sobre as benesses promovidas pela educação, assim, a instituição escolar nada mais é do que o espaço de dominação e opressão, dado que se torna um dos impasses a serem resolvidos pela professora Johnson de Mentes Perigosas.

Ao perceber que muitos de seus estudantes são latinos e apresentam dificuldades com a Língua Inglesa, a professora Johnson insere nos conteúdos a leitura de poemas e letras de música a fim de despertar o interesse da turma. As dificuldades de leitura são latentes, a relação dos estudantes com a disciplina também evidencia o distanciamento entre a língua estudada na escola e língua de suas práticas sociais. Em outras palavras, o descompasso latente está na legitimação da escola como reduto do saber institucionalizado, constrastando com a Língua Inglesa que faz parte das práticas sociais da comunidade no entorno da escola.

As tensões raciais também se destacam em ambas as narrativas. Por representarem o status quo, as professoras encontram resistências por parte dos estudantes e dos familiares para efetivar seu projeto pedagógico. As relações de poder entre negros e brancos, entre a comunidade e a escola, se concretizam na lógica colonialista em Mentes Perigosas, quando o diretor negro, sugere à estudante Callie, negra e grávida, a transferir-se para outra escola, pois sua gravidez não seria um bom exemplo para as demais adolescentes.

Além disso, outro embate é observado na (Figura 04), em que Johnson, incormodada pela ausência dos irmãos Durrell e Lionel em sua aula, decide buscálos em casa.

Figura 04

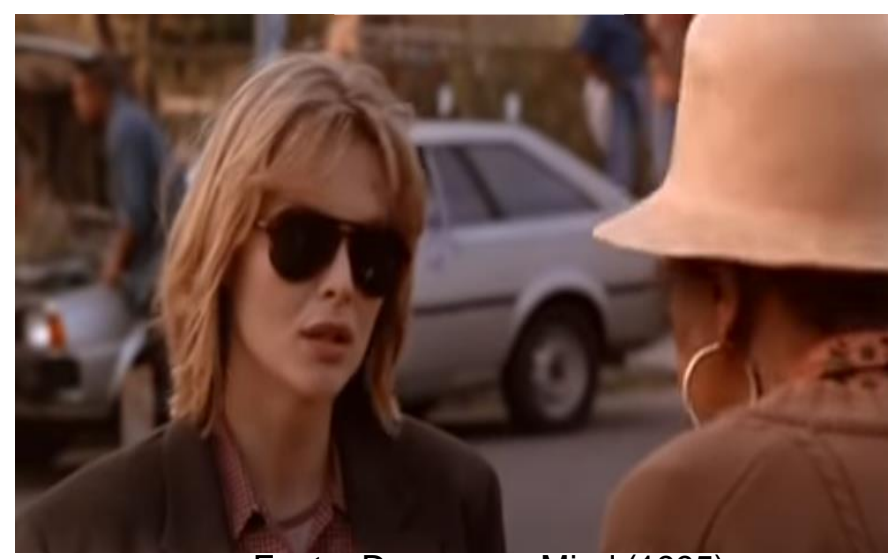

Fonte: Dangerous Mind (1995) 
Ms. Johnson: Hi. I'm Louanne Johnson. I'm the boys' teacher.

Durrell and Lionel's grandmother: I know who you are. You're that whitebread bitch messin' with my babies' minds.

Ms. Johnson: I beg your pardon?

Durrell and Lionel's grandmother: My boys don't go to your school no more, and that's gonna be it.

Ms. Johnson: You took them out of school?

Durrell and Lionel's grandmother: You're damn right I did. I saw what they were bringing home-poetry and shit. A waste of time. They got more important things to worry about.

Ms. Johnson: Don't you think that finishing high school will be valuable to their future?

Durrell and Lionel's grandmother: That's not in their future. I ain't raising no doctors and lawyers here. They got bills to pay. (DANGEROUS MIND, 1995).

Ambas as narrativas fílmicas focalizam a luta de forças entre o sistema opressor, representado pela gestão, pais e professores e de outro, a professora outsider, engajada e determinada a cumprir sua missão. Cann (2015), Baladeli (2019), destacam que a opressão retratada nas narrativas filmicas é operada pelo currículo obsoleto, gestão relapsa e ineficiente, professores displicentes, pais autoritários e desesperançosos com o sistema educacional. Segundo estudo de Baladeli (2019), os filmes sobre escola exploram à exaustão a superação de professores missionários, que subvertem as normas institucionais e enfrentam os opositores com abnegação.

No cinema, o professor representa a autoridade e o agente responsável pela imposição da cultura hegemônica, sistematizada no próprio currículo. Por essa razão o professor é visto pelos alunos como um opositor, que objetiva o enquadramento dos alunos ao conjunto de valores culturais que consideram opressores (BALADELI, 2019, p. 8).

Concordamos com Cann (2015), quando assevera, que os filmes propagam o ideário de que nestes espaços há a necessidade de um professor salvador, geralmente com pouca experiência docente, pois somente este personagem despido de formação teórica e prática está disposto a arriscar-se. A partir de tal receita hollywoodiana, bastaria a presença de uma professora outsider, branca, bem intencionada, disposta a correr riscos para instituir novos comportamentos nos estudantes. Tanto, que Johnson e Gruwell sofrem com as arbitrariedades da gestão escolar e com a resistência de familiares dos estudantes, que mostram-se desconfiados com a verdadeiras intenções das professoras. 


\section{Considerações finais}

Os filmes comerciais propagam vertiginosamente a naturalização da necessidade de um professor benevolente e disposto a transformar uma turma de estudantes indisciplinados, agressivos e sem perspectivas. Mentes Perigosas (1995) e Escritores da Liberdade (2007) não apresentam por acaso duas protagonistas brancas como representantes da cultura erudita, dos valores e costumes representativos dos interesses da elite que tem acesso à educação formal. Contudo, ainda que o tema enseja discussão no campo da formação de professores, não podemos desconsiderar o valor de entretenimento do cinema, bem como sua contribuição como produção estética.

Porém, no bojo do estudo em tela, o cinema como discurso exige análise crítica das representações que propaga, sobretudo, se alinharmos os resultados ao contexto da formação e atuação de professores de Língua Inglesa. Este estudo que teve como objetivo, discutir a partir do retrato de professoras protagonistas de Língua Inglesa no cinema, o ideário colonialista de educação, evidenciou que as duas narrativas fílmicas propagam professoras caricatas e romantizadas. Ambos os enredos exploram o personalismo como forma de escamotear as mazelas socioculturais e políticas que permeam os fenômenos educativos, sobretudo, nos processos de ensino de aprendizagem de Língua Inglesa.

Os filmes atribuem às ações de duas protagonistas brancas o poder de transformação e capacidade de conserto dos estudantes que apresentam desvios comportamentais e culturais. Jovens negros e latinos de escolas de periferia, conforme os filmes hollywoodianos são desinteressados pelos estudos, praticam a intolerância racial e cultural como forma de manifestar o seu descontentamento com o sistema escolar e sua condição social.

Por fim, as professoras outsider de Língua Inglesa das duas narrativas fílmicas atuam como mediadoras de um projeto de educação colonialista, em que os aspectos negativos da pobreza de jovens negros e latinos, são destacados e modificados à luz da Pedagogia do Herói ou de professoras brancas salvadoras.

\section{Referências Bibliográficas}


ARONSON, Brittany A. The white savior industrial complex: a cultural studies analysis of a teacher educator, savior film, and future teachers. Journal of Critical Thought and Praxis, v.6, n.3, p.36-54, 2017.

BALADELI, Ana P.D. Por dentro da escola: imagens do professor, do aluno e do currículo no filme Escritores da Liberdade. Itinerarius Reflections, v.15, n.1, 2019, p. 01-21.

BULMAN, Robert C. Teachers in the Hood: Hollywood's Middle-Class Fantasy. The Urban Review, v.34, n.3, sep./2002, p. 251-276.

CANN, Colette N. What school movies and TFA teach us about who should teach urban youth: dominant narratives as public pedagogy. Urban Education, v.50, n.3, p.288-315, 2015.

DALTON, Mary. The Hollywood curriculum teachers in the movies. $2^{\text {nd }}$ edition. Peter Lang: New York, 2010.

DANGEROUS MIND. Direção John N. Smith. Produção: Don Simpson e Jerry Bruckheimer, Elenco: Michelle Pfeiffer, Geoge Dzundza, Coutney B. Vance, Wade Dominguez, Hollywoord Pictures, 1995. 95min.

DULCI, Tereza M.S.. MALHEIROS, Mariana R. Um giro decolonial à metodologia científica: apontamentos epistemológicos para metodologias desde e para a América Latina. VII Encuentro de Estudios Sociales desde America Latina y el Caribe. Espirales, Ed. esp., p.174-193, jan. 2021.

FABRIS, Eli T. A. A pedagogia do herói nos filmes hollywoodianos. Currículo sem fronteiras, v. 10, n.1, p. 232-245, jan./jun.2010. Disponível em: < http://www.curriculosemfronteiras.org/vol10iss1articles/fabris.pdf > Acesso em 07 set. 2021.

FAIRCLOUGH, Norman. Media discourse. London: Edward Arnold, 1995.

FAIRCLOUGH, Norman. Discurso e mudança social. Revisão e tradução de Izabel Magalhães. Brasília: Editora Universidade de Brasília, 2001.

FREEDOM WRITERS. Direção: Richard Lagravenese. Produção: Danny DeVito, Michael Shamberg, Stacey Sher. Elenco: Hillary Swan, Patrick Dempsey. Paramount Picture, 2007. 122min.

hooks, bell. Teaching to transgress: education as the practice of Freedom. New York/London: Routledge, 1994.

MIGNOLO, Walter; VÁZQUEZ, Rolando. Pedagogía y (de)colonialidad. In: WALSH, C. Pedagogías decoloniales: práticas insurgentes de resistir, (re)existir y (re)vivir. Tomo II. Quito: Abya Yala, 2017. 
MOITA LOPES, Luiz P. Linguística Aplicada e vida contemporânea: problematização dos construtos que têm orientado a pesquisa. In: MOITA LOPES, L.P. (org.). Por uma Linguística Aplicada Indisciplinar. São Paulo: Parábola, 2006. p.85-105.

NOGUEIRA, Maria A.; CATANI, Afrânio. (orgs.). Escritos de Educação. 9. ed. Petrópolis, RJ: Vozes, 2007.

PEREIRA, Paula G. Reflexões críticas sobre o ensino-aprendizagem de Inglês como fator de inclusão ou exclusão social. Belt, Porto Alegre, v.6, n.1, p.12-28, 2015.

PHILLIPSON, Robert. Linguistic Imperialism. Oxford: OUP, 1992.

TAKAKI, Nara $H$. Exercising Southern and decolonial (self)critique in translanguaging: for a juntos stance. Revista X, Curitiba, v.15, n.1, p.32-54, 2020.

TEIXEIRA, Inês A.C.; GRAMMONT, Maria J.; AZEVEDO, Ana L.F. "Me ajuda a olhar!" O cinema na formação de professores (as). Educação em Foco, v.17, n.24, 2014, p.123-143.

Disponível em: <http://revista.uemg.br/index.php/educacaoemfoco/issue/view/31/showToc> acesso em 11 set. 2021.

ZAVALA, Miguel. Decolonial methodologies in Education. In: PETERS, M. A. (ed.). Encyclopedia of Educacional Philosophy and Theory. Springer, 2016, p.1-6. 